\title{
Manejo de plantas daninhas na cultura da melancia nos sistemas de plantio direto e convencional
}

\author{
Márcio Gledson O da Silva; Francisco Claudio L de Freitas; Maria Zuleide de Negreiros; Helida C de \\ Mesquita; Fabiana Aline O de Santana; Mayky Francley P de Lima \\ UFERSA, C. Postal 137, 59625-900 Mossoró-RN; m_gledson@yahoo.com.br
}

\begin{abstract}
RESUMO
Foram avaliadas estratégias de manejo de plantas daninhas sobre a produção de melancia, nos sistemas de plantio direto e convencional, em cultivo sucessivo ao meloeiro. O experimento foi conduzido em blocos casualisados com quatro repetições, no esquema de parcelas subdivididas. Nas parcelas foram avaliados dois sistemas de plantio (direto e convencional) e, nas sub-parcelas, nove sistemas de manejo de plantas daninhas [cobertura com filme de polietileno; com capinas aos 14 dias após o transplantio (DAT); aos 14 e 28 DAT; 14 e 42 DAT; aos 14, 28 e 42 DAT; aos 28 DAT; aos 28 e 42 DAT; aos 42 DAT e testemunha sem capinas]. Antes da implantação do experimento, a área foi cultivada com meloeiro nos respectivos sistemas de plantio, tendo-se reutilizado a palhada nos tratamentos com sistema de plantio direto e o filme de polietileno nos tratamentos com uso desse material nos dois sistemas de cultivo. Aos 14, 28 e 42 DAT e por ocasião da colheita da melancia (80 DAT), foram realizadas avaliações de densidade e massa seca de plantas daninhas. Para a melancia, foram avaliados o número de frutos comercializáveis por planta; número total de frutos por planta; massa média de frutos comercializáveis por planta; massa média de frutos (totais) por planta; produtividade comercializável e total. O sistema de plantio direto induziu redução da densidade e da massa seca das plantas daninhas, com necessidade de realização de uma única capina entre 28 e 42 DAT, enquanto que no plantio convencional foram necessárias duas capinas, aos 14 e 28 DAT. Quando a cultura conviveu com as plantas daninhas durante todo o ciclo, houve redução de 100 e $35,7 \%$ na produtividade de frutos comercializáveis para os sistemas de plantio convencional e direto, respectivamente. O sistema de plantio direto e o filme de polietileno no plantio convencional permitem a realização do cultivo da melancia em sucessão ao meloeiro, reduzindo a interferência de plantas daninhas e proporcionando produtividade satisfatória.
\end{abstract}

Palavras-chave: Citrullus lanatus, cobertura morta, filme de polietileno.

\begin{abstract}
Weed management in watermelon crop in no-tillage and conventional systems
\end{abstract}

We evaluated strategies for weed management on the production of watermelon in no-tillage and conventional systems, in successive cultivation to the melon crop. The research was carried out in split plots, distributed in the experimental design of randomized blocks. Two cropping systems were evaluated in the plots (no-tillage and conventional tillage) and in the sub-plots were evaluated nine strategies of weed management [covered with polyethylene film, with weeding at 14 days after transplanting (DAT); 14 and 28 DAT, 14 and 42 DAT; 14, 28 and 42 DAT; 28 DAT, 28 and 42 DAT; 42 DAT and control without weeding]. Before the implantation of the experiment, the area was cultivated with melon in the respective cropping systems, the straw mulch being used again in the treatments with no-tillage system, as well as polyethylene film in the treatments with use of this material in two cropping systems. At 14, 28 and 42 DAT and at harvest of watermelon ( 80 DAT), were assessed the density and dry mass of weeds. The weeds were cut at ground level, separated by species, counted and put into oven with forced air at $65^{\circ} \mathrm{C}$ until constant weight to determine dry mass. From the watermelon crop were evaluated the number of marketable fruits, total number of fruits, average mass of marketable fruits per plant and average fruit mass (total) per plant and marketable and total yield. The no-tillage system reduced the density and dry mass of weeds, requiring only one weeding between 14 and 42 DAT, whereas in the conventional tillage system two weedings were needed, at 14 and 28 DAT. When the crop was maintained without weeding throughout the cycle, there was a reduction of 100 and $35.7 \%$ in marketable fruit yields in conventional and no-tillage systems, respectively. The no-tillage and polyethylene film in conventional tillage system enabled the cultivation of watermelon in succession to the melon crop, reducing weed interference and providing satisfactory productivity.

Keywords: Citrullus lanatus, straw mulch, polyethylene mulching.

(Recebido para publicação em 11 de setembro de 2012; aceito em 24 de julho de 2013) (Received on September 11, 2012; accepted on July 24, 2013)

\begin{abstract}
A melancia é uma das principais Cucurbitaceae cultivadas no Brasil, com 95.319 ha cultivados e produtividade de 21,67 $\mathrm{tha}^{-1}$. A região Nordeste é responsável por $35,76 \%$ da produção nacional, destacando-se os estados da Bahia (398.866 t ano ${ }^{-1}$ ), Pernambuco (104.300 t ano-1), Rio
\end{abstract}

Grande do Norte (73.731 t ano $\left.{ }^{-1}\right)$, Piauí $\left(60.478 \mathrm{t} \mathrm{ano}^{-1}\right)$ e Ceará $\left(51.281 \mathrm{t} \mathrm{ano}^{-1}\right)$ (IBGE, 2009).

Apesar do discreto aumento nos últimos anos, a produção da melancia no Brasil ainda é bastante limitada devido a diversos fatores, como o pouco interesse das indústrias em estimular o desenvol- vimento dessa cultura, da sazonalidade nos preços recebidos pelo produtor e dos problemas agronômicos da cultura, como a baixa produtividade e qualidade do fruto colhido (Junior et al., 2006).

A qualidade final das hortaliças está relacionada, direta e indiretamente, a numerosos fatores intrínsecos e extrín- 
secos, que atuam durante todas as fases de crescimento e desenvolvimento das plantas. Dentre esses fatores, merece destaque a interferência de plantas daninhas, que competem com a cultura por água, luz e nutrientes, além de liberarem substâncias alelopáticas que inibem o desenvolvimento das espécies cultivadas (Fernandes, 2010; Soares et al., 2010). Essa interferência pode resultar em até $95 \%$ de perda na produtividade da melancieira (Medeiros et al., 2000).

O controle de plantas daninhas em hortaliças como melão e melancia vem sendo realizado normalmente com a cobertura do solo com filme de polietileno devido à pouca disponibilidade de herbicidas registrados para as culturas e à dificuldade da realização do controle mecânico, em função do hábito de crescimento prostrado das plantas (Tomaz, 2008).

Além de exercer controle eficiente sobre as plantas daninhas, o filme de polietileno aumenta a eficiência de uso da água pela cultura, pois funciona como barreira física reduzindo a evaporação da água na superfície do solo (Caron \& Heldwein, 2000; Teofilo et al., 2012). No entanto, devido aos custos elevados da matéria prima e da mão-de-obra, na colocação do filme no campo, esse método é mais empregado em cultivos de maior valor agregado, como a produção de frutos de melão destinados ao mercado externo. Após a primeira colheita dessa cultura é comum os produtores realizarem um segundo cultivo na área no sentido de minimizar os custos e aproveitar melhor esse material, sem realizar um novo preparo do solo. Neste caso, uma das culturas utilizadas tem sido a melancia, por apresentar maior rusticidade em relação à cultura antecessora.

Outra técnica utilizada no intuito de diminuir a interferência das plantas daninhas é o sistema de plantio direto na palha (Tomaz, 2008; Silva Hirata et al., 2009; Fernandes, 2010; Teofilo et al., 2012). Dependendo de fatores como local e pressão de plantas daninhas, a ausência de revolvimento do solo e a cobertura morta com palha pode até eliminar a necessidade de aplicação de herbicidas (Smeda \& Weller, 1996). Além disso, o sistema de plantio direto reduz as perdas de solo por erosão hí- drica e eólica, reduz o assoreamento e a eutrofização de represas, rios e riachos, melhora as características físicas do solo, elevando também sua capacidade de infiltração e retenção de água elevando também seu teor de matéria orgânica (Agnes et al., 2004; Freitas et al., 2005). Na cultura do melão, Teófilo et al. (2012) verificaram que a cobertura do solo com filme de polietileno ou palhada no sistema de plantio direto reduziram a infestação de plantas daninhas e reduziram o consumo de água em relação ao solo sem cobertura no plantio convencional com aração e gradagem.

Objetivou-se com este trabalho avaliar estratégias de manejo de plantas daninhas na cultura da melancia em sucessão ao cultivo do melão nos sistemas de plantio direto e convencional.

\section{MATERIAL E MÉTODOS}

O trabalho foi desenvolvido de dezembro de 2008 a março de 2009 na horta experimental do campus da Universidade Federal Rural do Semiárido em Mossoró-RN. O clima da região é quente e seco, com precipitação pluviométrica média anual de 673,9 mm, distribuídos no período de fevereiro a junho; temperatura e umidade relativa do ar média de $27^{\circ} \mathrm{C}$ e $68,9 \%$, respectivamente (Carmo Filho \& Oliveira, 1995).

Foram avaliados dois sistemas de plantio (direto e convencional) e nas sub-parcelas nove sistemas de manejo de plantas daninhas [cobertura com filme de polietileno; com capinas aos 14 dias após o transplantio (DAT); aos 14 e 28 DAT; 14 e 42 DAT; aos 14, 28 e 42 DAT; aos 28 DAT; aos 28 e 42 DAT; aos 42 DAT e testemunha sem capinas]. O esquema foi em parcelas subdivididas, com os sistemas de plantio compondo as parcelas e os de manejo de plantas daninhas, as subparcelas. $\mathrm{O}$ delineamento foi blocos casualizados, com quatro repetições.

Antes da implantação do experimento, a área foi cultivada com meloeiro no período de outubro a dezembro de 2008 , sendo que nas parcelas cultivadas no sistema de plantio direto (SPD), para obtenção da palhada, foi realizado, em fevereiro de 2008, plantio da cultura do milho em consorciação com Brachiaria brizantha. Após a colheita do milho, a forrageira cresceu livremente até o mês de julho, quando foi dessecada com 1,9 $\mathrm{kg} \mathrm{ha}^{-1}$ do herbicida glyphosate. A massa seca da palhada formada pela braquiária e pelos restos culturais do milho foi de 8,0 $\mathrm{t} \mathrm{ha}^{-1}$. Nas parcelas cultivadas no sistema de plantio convencional (SPC), realizou-se também o cultivo do milho em consorciação com braquiária no mesmo período. No entanto, uma semana antes do transplantio das mudas de melão esse material foi incorporado ao solo por meio de uma aração e duas gradagens.

Após a colheita do melão, nas parcelas de SPD, foi efetuada dessecação com $1,9 \mathrm{~kg} \mathrm{ha}^{-1}$ do herbicida glyphosate e retiradas amostras da palha, onde verificaram-se em média, 5,0 $\mathrm{t} \mathrm{ha}^{-1} \mathrm{de}$ massa seca. Nas parcelas com SPC, realizou-se novo preparo do solo, por meio de capina manual com enxada. Nos tratamentos com filme de polietileno, as parcelas foram mantidas no mesmo local do cultivo do melão, para reutilização do mesmo.

O transplantio da melancia foi feito com mudas produzidas em bandejas de poliestireno expandido com 128 células, no espaçamento de 1,80 m entre fileiras x 0,40 m entre plantas na fileira. As parcelas foram constituídas de três linhas de $6 \mathrm{~m}$ de comprimento, sendo as duas fileiras das extremidades consideradas como bordaduras. A área útil foi constituída das 9 plantas centrais da linha central.

Foi utilizado o sistema de irrigação localizado por gotejamento com emissores espaçados de $0,4 \mathrm{~m}$ e vazão de $1,7 \mathrm{~L}$ $\mathrm{h}^{-1}$. O manejo da água foi realizado com base na curva característica de água no solo para cada sistema de plantio a 15 e $30 \mathrm{~cm}$ de profundidade (Figura 1), de modo a manter o solo com umidade superior a $75 \%$ da água disponível total; por ocasião das irrigações de cada tratamento, a umidade do solo foi elevada para valores correspondentes ao potencial matricial, média nas duas profundidades, de cerca de $-3 \mathrm{kPa}$ (capacidade de campo). Com base nessas informações, foram aplicadas lâminas diferenciadas para cada tratamento. As 
adubações foram realizadas via água de irrigação, utilizando-se $348,0 \mathrm{~kg} \mathrm{ha}^{-1}$ de $\mathrm{N} ; 241,0 \mathrm{~kg} \mathrm{ha}^{-1}$ de $\mathrm{P}_{2} \mathrm{O}_{5}$ e $274,0 \mathrm{~kg}$ $\mathrm{ha}^{-1}$ de $\mathrm{K}_{2} \mathrm{O}$, na forma de ureia, MAP e cloreto de potássio, respectivamente, segundo metodologia adotada pelos produtores da região (Tomaz, 2008).

Aos 14, 28 e 42 DAT e por ocasião da colheita da melancia ( $80 \mathrm{DAT})$, foram realizadas avaliações de densidade e massa seca de plantas daninhas. Para tal, foram realizadas, em cada subparcela, três amostragens em quadrados com $0,50 \mathrm{~m}$ de lado $\left(0,25 \mathrm{~m}^{2}\right)$. As plantas daninhas foram cortadas ao nível do solo, separadas por espécie, contadas e levadas à estufa com circulação forçada de ar à temperatura de $65^{\circ} \mathrm{C}$, até massa constante, para determinação da massa seca.

Da cultura da melancia, foram colhidos os frutos de nove plantas por subparcela, os quais foram contados e classificados em comercializáveis e não-comercializáveis, segundo classificação proposta pelas empresas da região. Considerou-se como não-comercializáveis os frutos com defeitos de formação, injúrias mecânicas, danificados por patógenos ou com tamanho inferior a $2,1 \mathrm{~kg}$. Com base nessas informações, obtiveram-se as seguintes características: número de frutos comercializáveis por planta; número total de frutos por planta; massa média de frutos comerciais por planta; massa média de frutos (totais) por planta; produtividade comercializável e total.

Os dados foram submetidos à análise de variância, pelo teste $\mathrm{F}$ e, em caso de significância, ao teste de Tukey, a 5\% de probabilidade, utilizando-se o programa SAEG.

\section{RESULTADOS E DISCUSSÃO}

As principais espécies de plantas daninhas que ocorreram na área experimental foram bredo (Triantema portucastrum), caruru (Amaranthus spinosus), jitirana (Merremia aegyptia), capim-milhã (Digitaria bicornis), tiririca (Cyperus rotundus), trapoeraba (Commelina benghalensis), mussambê (Cleome affinis) e quebra-pedra (Phyllanthus niruri).

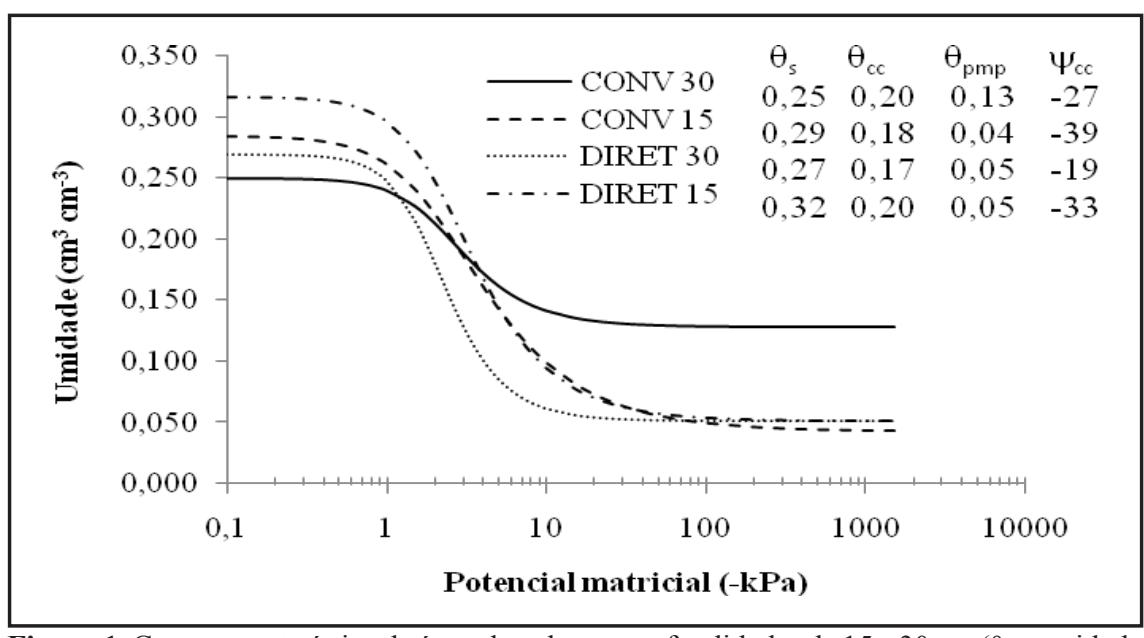

Figura 1. Curva característica de água do solo nas profundidades de 15 e $30 \mathrm{~cm}\left(\theta_{\mathrm{s}}=\right.$ umidade do solo no ponto de saturação; $\theta_{\mathrm{cc}}=$ umidade do solo na capacidade de campo; $\theta_{\mathrm{pmp}}=$ umidade do solo no ponto de murcha permanente; $\Psi_{\mathrm{cc}}=$ umidade do solo no potencial matricial) nos sistema de plantio direto e convencional [soil-water characteristic curve in the depths of 15 and $30 \mathrm{~cm}\left(\theta_{\mathrm{s}}=\right.$ soil moisture at the point of saturation; $\theta_{\mathrm{cc}}=$ soil moisture at field capacity; $\theta_{\mathrm{pmp}}=$ soil moisture at wilting point; $\Psi_{\mathrm{cc}}=$ soil moisture in the matric potential) in no-tillage and conventional sistems]. Mossoró, UfFERSA, 2009.

Nas características densidade e massa seca de plantas daninhas verificou-se interação entre os sistemas de cultivo (SPD e SPC) e estratégias de manejo. No SPC, a menor densidade de plantas daninhas foi observada com filme de polietileno e com capinas aos 14, 28 e 42 DAT, enquanto que no SPD não houve variação no número de plantas infestantes entre as estratégias de manejo de plantas daninhas (Tabela 1). Quando se compararam os sistemas de plantio dentro de cada estratégia de manejo de plantas daninhas, o SPD apresentou menor população de plantas infestantes em todas as estratégias de controle avaliadas, com exceção do uso do filme de polietileno que restringiu a emergência das mesmas nos dois sistemas de plantio. Segundo Correia et al. (2006), a composição e as densidades populacionais das comunidades infestantes são influenciadas pelos sistemas de produção.

O menor acúmulo de massa seca no SPC foi verificado quando se utilizou o filme de polietileno, enquanto que maiores valores foram observados onde não foram feitas capinas e com capinas somente aos 14 DAT, devido ao maior espaço de tempo até a colheita, favorecendo crescimento das plantas após a reinfestação. No SPD, não houve variação no acúmulo de massa seca de plantas infestantes entre as estratégias de manejo de plantas daninhas, com exceção do uso do filme de polietileno. Quando se compararam os sistemas de plantio dentro de cada estratégia de manejo de plantas daninhas, o SPD apresentou menores valores em todas as estratégias de controle avaliadas, com exceção do uso do filme de polietileno e com capinas aos 14, 28 e 42 DAT.

A maior reinfestação observada no SPC, que foi capinado com enxadas, deve-se ao revolvimento do solo, que estimula a germinação de sementes de plantas daninhas, especialmente, às fotoblásticas positivas, que têm sua dormência quebrada pela exposição à luz durante a capina, e ao grande distúrbio no solo, como aração, gradagem, enxadas, facilitando a ocorrência de elevadas populações de plantas daninhas na área [Silva Hirata et al. (2009), citando Piteli (1984) e Pereira (1987)]. Por outro lado, no plantio direto, as poucas plantas infestantes foram removidas do solo por meio de arranque manual, sem revolvimento do solo, preservando sua cobertura com a palhada. Já, o filme de polietileno controlou com eficiência as plantas daninhas nos dois sistemas de plantio.

Com relação às características avaliadas na melancia, verificou-se interação entre os sistemas de cultivo 
Tabela 1. Densidade e massa seca de plantas daninhas na cultura da melancia em função dos sistemas de plantio e estratégias de manejo de plantas daninhas, por ocasião da colheita (density and dry weight of weeds in watermelon crop in terms of crop management systems and strategies for weed management at the time of harvest). Mossoró, UFERSA, 2009.

\begin{tabular}{|c|c|c|c|}
\hline & Manejo de plantas daninhas & Densidade (plantas $\mathrm{m}^{-2}$ ) & Massa seca $\left(\mathrm{g} \mathrm{m}^{-2}\right)$ \\
\hline \multirow{9}{*}{ 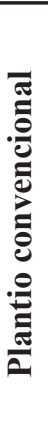 } & Sem capina & $(405,7) 40,16 \mathrm{abA}^{*}$ & $(1410,8) 74,27 \mathrm{aA}^{*}$ \\
\hline & Capina aos 14 DAT & $(386,0) 43,78 \mathrm{abA}$ & $(1520,8) 83,00 \mathrm{aA}$ \\
\hline & Capinas aos 28 DAT & $(569,2) 48,27 \mathrm{abA}$ & $(396,3) 42,70 \mathrm{bA}$ \\
\hline & Capina aos 42 DAT & $(376,9) 38,55 \mathrm{abA}$ & $(486,6) 42,10 \mathrm{bA}$ \\
\hline & Capinas aos 14 e 28 DAT & $(333,5) 33,96 \mathrm{abA}$ & $(354,8) 40,49 \mathrm{bA}$ \\
\hline & Capinas aos 14 e 42 DAT & $(373,1) 37,78 \mathrm{abA}$ & $(399,1) 35,48 \mathrm{bA}$ \\
\hline & Capinas aos 28 e 42 DAT & $(527,3) 49,99 \mathrm{aA}$ & $(332,5) 43,39 \mathrm{bA}$ \\
\hline & Capinas aos 14,28 e 42 DAT & $(238,1) 30,57 \mathrm{bA}$ & $(203,4) 27,36 \mathrm{bA}$ \\
\hline & Filme de polietileno & $(0,0) 5,66 \mathrm{cA}$ & $(0,0) 5,66 \mathrm{cA}$ \\
\hline \multirow{9}{*}{ 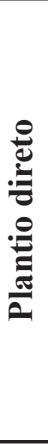 } & Sem capina & $(46,2) 14,78 \mathrm{aB}$ & $(178,9) 25,32 \mathrm{abB}$ \\
\hline & Capina aos 14 DAT & $(63,3) 17,25 \mathrm{aB}$ & $(132,6) 24,24 \mathrm{abB}$ \\
\hline & Capinas aos 28 DAT & $(41,3) 13,65 \mathrm{aB}$ & $(165,9) 22,26 \mathrm{abB}$ \\
\hline & Capina aos 42 DAT & $(52,8) 16,02 \mathrm{aB}$ & $(123,8) 21,93 \mathrm{abB}$ \\
\hline & Capinas aos 14 e 28 DAT & $(40,0) 13,27 \mathrm{aB}$ & $(181,2) 23,94 \mathrm{abB}$ \\
\hline & Capinas aos 14 e 42 DAT & $(64,2) 17,12 \mathrm{aB}$ & $(156,2) 21,27 \mathrm{abB}$ \\
\hline & Capinas aos 28 e 42 DAT & $(59,7) 16,85 \mathrm{aB}$ & $(278,7) 29,38 \mathrm{aB}$ \\
\hline & Capinas aos 14,28 e 42 DAT & $(55,9) 16,05 \mathrm{aB}$ & $(208,8) 23,65 \mathrm{abA}$ \\
\hline & Filme de polietileno & $(0,0) 5,66 \mathrm{aA}$ & $(0,0) 5,66 \mathrm{bA}$ \\
\hline \multicolumn{2}{|c|}{$\mathrm{CV}(\%)$} & 30,71 & 27,21 \\
\hline
\end{tabular}

*Nas colunas, letras minúsculas comparam as modalidades de manejo de plantas daninhas dentro de cada sistema de plantio pelo teste de Tukey $(\mathrm{p} \leq 0,05)$ e, nas linhas, letras maiúsculas, comparam sistemas de plantio, dentro de cada modalidade de manejo de plantas daninhas, pelo teste $\mathrm{F}(\mathrm{p} \leq 0,05)$. Os dados foram transformados por $(\mathrm{x}+0,5)^{0,5}$ e os valores originais estão entre parênteses $(*$ in the columns, tiny letters compare the methods of weed management within each cropping system by Tukey test $(\mathrm{p} \leq 0.05)$ and capital letters compare cropping systems within each type of weed management by $\mathrm{F}$ test $(\mathrm{p} \leq 0.05)$. The data were transformed by $(\mathrm{x}+0.5)^{0.5}$ and the original values are in parentheses).

(SPD e SPC) e estratégias de manejo de plantas daninhas para as seguintes características: número de frutos comercializáveis por planta; número total de frutos por planta; massa média frutos comercializáveis por planta; massa média frutos (totais) por planta; produtividade comercializável e total.

Quando se compararam as estratégias de manejo de plantas daninhas dentro do sistema de plantio convencional, verificou-se, na ausência das capinas, que não houve produção de frutos comercializáveis (Tabela 2), como consequência da intensa competição exercida pelas plantas daninhas. Esses resultados corroboram com Tomaz (2008); Fernandes (2010) e Teófilo et al. (2012), que verificaram $100 \%$ de perda na produção comercializável de frutos de melão, no mesmo sistema de plantio, devido à interferência de plantas daninhas e superiores aos verificados por Maciel et al. (2008), que constataram redução de $58,6 \%$ na produtividade de melancia, quando a cultura conviveu com as plantas infestantes durante todo o ciclo.

Quando se realizou apenas uma capina aos 14 ou aos 42 DAT, também se verificou perda de $100 \%$ de frutos comercializáveis e menor valor observado nas demais características avaliadas, devido à reinfestação ocorrida após a capina realizada aos 14 DAT. Já, quando se capinou apenas aos 42 DAT a maior interferência deveu-se ao longo período de convivência das plantas infestantes com a cultura.

Quando se realizou duas capinas, aos 14 e 42 DAT ou aos 28 e 42 DAT no SPC, houve redução no número de frutos e na massa média de frutos comercializáveis por planta, o que resultou na diminuição da produtividade, quando comparados aos tratamentos com duas ou três capinas, aos 14 e 28 DAT e aos
14, 28 e 42 DAT, respectivamente (Tabela 2). Todavia, os tratamentos no SPC com duas capinas, aos 14 e 28 DAT, e com três capinas, aos 14, 28 e 42 DAT, não diferiram entre si com relação à produtividade, indicando que a cultura da melancia necessita da realização de duas capinas até os 28 DAT, e a partir desse momento, as plantas que emergirem não vão mais interferir na produtividade da cultura. Para a cultura do melão, Fernandes (2010) também não verificou efeito de capinas após os 28 DAT, quando cultivado no sistema de plantio convencional.

O filme de polietileno se destacou entre os demais sistemas de controle de plantas daninhas no SPC, obtendo-se maior produtividade, como consequência da combinação entre maior número de frutos comerciais e frutos maiores, demonstrando a eficiência do filme de polietileno no controle das plantas da- 
Tabela 2. Número de frutos comercializáveis e totais por planta; massa média de frutos comercializáveis e totais e produtividade comercializável e total na cultura da melancia em função dos sistemas de plantio e estratégias de manejo de plantas daninhas (number of marketable fruits and total fruits per plant, average weight of marketable and total fruits and marketable and total yield of watermelon crop in different cropping systems and strategies for weed management). Mossoró, UFERSA, 2009.

\begin{tabular}{llccccc}
\hline Manejo de plantas daninhas & $\begin{array}{c}\mathbf{N}^{\circ} \text { frutos } \\
\text { comerc// } \\
\text { planta }\end{array}$ & $\begin{array}{c}\mathbf{N}^{\circ} \text { total } \\
\text { de frutos/ } \\
\text { planta }\end{array}$ & $\begin{array}{c}\text { Massa média } \\
\text { frutos comerc. } \\
\text { (kg) }\end{array}$ & $\begin{array}{c}\text { Massa média } \\
\text { frutos totais } \\
\text { (kg) }\end{array}$ & $\begin{array}{c}\text { Produtiv. } \\
\text { comercial } \\
\text { (t/ha) }\end{array}$ & $\begin{array}{c}\text { Produtiv. } \\
\text { total } \\
\text { (t/ha) }\end{array}$ \\
\hline Sem capina & $0,00 \mathrm{cB} *$ & $0,21 \mathrm{cB}$ & $0,00 \mathrm{~dB}$ & $0,48 \mathrm{deB}$ & $0,00 \mathrm{cB} *$ & $1,25 \mathrm{cB}$ \\
Capinado aos 14 DAT & $0,00 \mathrm{cB}$ & $0,29 \mathrm{cB}$ & $0,00 \mathrm{~dB}$ & $0,44 \mathrm{deB}$ & $0,00 \mathrm{cB}$ & $1,76 \mathrm{cB}$ \\
Capinado aos 28 DAT & $0,34 \mathrm{bcB}$ & $1,56 \mathrm{abcB}$ & $2,21 \mathrm{abB}$ & $1,26 \mathrm{bcB}$ & $10,46 \mathrm{bcB}$ & $26,08 \mathrm{bcB}$ \\
Capinado aos 42 DAT & $0,00 \mathrm{cB}$ & $0,29 \mathrm{cB}$ & $0,00 \mathrm{~dB}$ & $0,14 \mathrm{eB}$ & $0,00 \mathrm{cB}$ & $1,12 \mathrm{cB}$ \\
Capinado aos 14 e 28 DAT & $0,96 \mathrm{abB}$ & $2,23 \mathrm{abA}$ & $2,52 \mathrm{aA}$ & $1,71 \mathrm{abB}$ & $33,51 \mathrm{abB}$ & $53,32 \mathrm{abB}$ \\
Capinado aos 14 e 42 DAT & $0,04 \mathrm{cB}$ & $0,96 \mathrm{cB}$ & $0,52 \mathrm{cdB}$ & $0,53 \mathrm{deB}$ & $1,04 \mathrm{cB}$ & $9,95 \mathrm{cB}$ \\
Capinado aos 28 e 42 DAT & $0,07 \mathrm{cB}$ & $1,20 \mathrm{cB}$ & $1,23 \mathrm{bcB}$ & $0,98 \mathrm{~cd} \mathrm{~B}$ & $2,45 \mathrm{cB}$ & $15,47 \mathrm{cB}$ \\
Capinado aos 14; 28 e 42 DAT & $0,85 \mathrm{abB}$ & $2,45 \mathrm{abA}$ & $2,25 \mathrm{abB}$ & $1,50 \mathrm{bcB}$ & $26,74 \mathrm{bcB}$ & $51,47 \mathrm{abB}$ \\
Filme de Polietileno & $1,49 \mathrm{aB}$ & $2,46 \mathrm{aA}$ & $2,77 \mathrm{aA}$ & $2,22 \mathrm{aB}$ & $57,47 \mathrm{aB}$ & $75,88 \mathrm{aB}$ \\
\hline Sem capina & $1,32 \mathrm{bA}$ & $1,64 \mathrm{aA}$ & $2,96 \mathrm{aA}$ & $2,74 \mathrm{aA}$ & $53,95 \mathrm{cA}$ & $60,79 \mathrm{bA}$ \\
Capinado aos 14 DAT & $1,54 \mathrm{abA}$ & $1,75 \mathrm{aA}$ & $2,93 \mathrm{aA}$ & $2,77 \mathrm{aA}$ & $61,75 \mathrm{bcA}$ & $67,08 \mathrm{bA}$ \\
Capinado aos 28 DAT & $2,00 \mathrm{abA}$ & $2,25 \mathrm{aA}$ & $2,94 \mathrm{aA}$ & $2,79 \mathrm{aA}$ & $81,34 \mathrm{abA}$ & $86,80 \mathrm{abA}$ \\
Capinado aos 42 DAT & $1,69 \mathrm{abA}$ & $1,96 \mathrm{aA}$ & $3,05 \mathrm{aA}$ & $2,86 \mathrm{aA}$ & $70,98 \mathrm{abA}$ & $77,15 \mathrm{abA}$ \\
Capinado aos 14 e 28 DAT & $1,75 \mathrm{abA}$ & $2,06 \mathrm{aA}$ & $2,99 \mathrm{aA}$ & $2,81 \mathrm{aA}$ & $71,60 \mathrm{abA}$ & $78,66 \mathrm{abA}$ \\
Capinado aos 14 e 42 DAT & $1,64 \mathrm{abA}$ & $1,75 \mathrm{aA}$ & $3,21 \mathrm{aA}$ & $3,13 \mathrm{aA}$ & $73,33 \mathrm{abA}$ & $76,11 \mathrm{abA}$ \\
Capinado aos 28 e 42 DAT & $1,71 \mathrm{abA}$ & $2,00 \mathrm{aA}$ & $2,84 \mathrm{aA}$ & $2,69 \mathrm{aA}$ & $67,27 \mathrm{abA}$ & $73,89 \mathrm{abA}$ \\
Capinado aos 14; 28 e 42 DAT & $1,90 \mathrm{abA}$ & $2,14 \mathrm{aA}$ & $3,17 \mathrm{aA}$ & $3,05 \mathrm{aA}$ & $83,39 \mathrm{abA}$ & $89,13 \mathrm{abA}$ \\
Filme de Polietileno & $2,20 \mathrm{aA}$ & $2,39 \mathrm{aA}$ & $3,12 \mathrm{aA}$ & $3,04 \mathrm{aA}$ & $94,49 \mathrm{aA}$ & $99,70 \mathrm{aA}$ \\
\hline CV (\%) & 29,536 & 26,109 & 20,819 & 14,187 & 27,663 & 24,546 \\
\hline
\end{tabular}

*Nas colunas, letras minúsculas comparam as modalidades de manejo de plantas daninhas dentro de cada sistema de plantio pelo teste de Tukey $(\mathrm{p} \leq 0,05)$ e, nas linhas, letras maiúsculas comparam sistemas de plantio, dentro de cada modalidade de manejo de plantas daninhas, pelo teste $\mathrm{F}(\mathrm{p} \leq 0,05)$ [*in the columns, tiny letters compare the methods of weed management within each cropping system by Tukey test $(\mathrm{p} \leq 0.05)$ and capital letters compare cropping systems within each type of weed management by $\mathrm{F}$ test $(\mathrm{p} \leq 0.05)]$.

ninhas (Tabela 2). No sistema de plantio direto, não houve variação do número de frutos totais por planta e da massa média de frutos comerciais e totais entre as estratégias de manejo de plantas daninhas adotadas.

Apesar da redução na infestação de plantas daninhas, em relação ao SPC, os tratamentos sem capinas e com apenas uma capina aos 14 DAT no SPD resultaram em produtividade inferior às demais estratégias de controle, com perdas de 35,7 e $25,9 \%$, respectivamente, em relação ao tratamento com capinas aos 14, 28 e 42 DAT. Essa redução é semelhante à obtida por Fernandes (2010) na cultura do melão, ao constatar redução na produtividade comercial de $28,8 \%$, quando a cultura conviveu com as plantas daninhas durante todo o ciclo, comparado ao submetido a três capinas no sistema de plantio direto. No entanto, a realização de apenas uma capina entre 28 e 42 DAT foi suficiente para evitar a interferência das plantas daninhas sobre a produtividade comercial da melancia. A utilização do filme de polietileno no sistema de plantio direto sobre a palhada, promoveu incremento no número de frutos e na produtividade comercial e total por planta (Tabela 2).

Quando se compararam os efeitos dos sistemas de plantio dentro de cada estratégia de manejo de plantas daninhas, verifica-se que com o SPD obtiveram-se melhores resultados em todas as estratégias de controle para o número de frutos totais, massa média de frutos totais e produtividade comercializável e total, enquanto que para o número de frutos comerciais por planta $\mathrm{e}$ massa média de frutos comercializáveis, as estratégias com capinas aos 14,28 e 42 DAT, e com filme de polietileno não diferiram entre os dois sistemas de plantio. Resultados semelhantes foram obtidos por Tomaz (2008) e Fernandes (2010) trabalhando com manejo de plantas daninhas no sistema de plantio direto e convencional na cultura do melão.

A redução da necessidade de capinas do SPD em relação ao SPC se deve à menor infestação de plantas daninhas no SPD, como consequência dos efeitos da cobertura do solo. Isso porque, de acordo com Silva Hirata et al. (2009), a palhada apresenta efeito físico, químico e biológico na supressão de plantas daninhas. Embora dependendo de fatores como local e pressão de plantas daninhas, a palhada pode até eliminar a necessidade de aplicação de herbicidas ou realização de capinas (Smeda \& 
Weller, 1996).

A baixa taxa de decomposição da palhada durante o cultivo do meloeiro em decorrência da reduzida exposição à umidade, devido à baixa probabilidade de ocorrência de chuvas no período de cultivo do meloeiro na região semiárida do Nordeste brasileiro e ao sistema de irrigação localizada por gotejamento, que fornece água apenas junto à planta sem molhar a cobertura morta, viabiliza o cultivo da melancia, assim como outras culturas, em sucessão ao meloeiro no sistema de plantio direto. Silva et al. (2009), trabalhando com a cultura do tomate em plantio direto no estado de São Paulo, no período de baixa precipitação, verificaram que a decomposição da palhada foi muito lenta, devido à baixa pluviosidade no período e, segundo esses autores, a irrigação por gotejamento auxilia na persistência da palhada sobre a superfície do solo, uma vez que esta não é molhada durante a irrigação.

Com base nos resultados obtidos, pode-se concluir que o cultivo da melancia em sucessão ao meloeiro no sistema de plantio direto proporcionou maior produtividade de frutos que o sistema de plantio convencional. Quando o cultivo da melancia foi realizado no sistema de plantio direto houve menor infestação de plantas daninhas, com necessidade de realização de uma única capina entre 28 e 42 DAT e, no sistema de plantio convencional foram necessárias duas capinas, aos 14 e 28 DAT.

\section{REFERÊNCIAS}

AGNES EL; FREITAS FCL; FERREIRA LR. 2004. Situação atual da integração agricultura pecuária em Minas Gerais e na Zona da Mata Mineira. In: ZAMBOLIM L; FERREIRA AA; AGNES EL (eds). Manejo integrado: Integração agricultura-pecuária. Viçosa-MG, p. 251-267.

CARMO FILHO F; OLIVEIRA OF. 1995. Mossoró: um município do semi-árido nordestino, caracterização climática e aspecto florístico. Mossoró: ESAM. p.62. (Coleção Mossoroense, série B).

CARON BO; HELDWEIN AB. 2000. Consumo d'água e coeficiente de cultura para o meloeiro cultivado em estufa plástica na primavera. Revista Brasileira de Agrometeorologia 8: 19-25.

CORREIA NM; DURIGAN JC; KLINK UP. 2006. Influência do tipo e da quantidade de resíduos vegetais na emergência de plantas daninhas. Planta Daninha 24: 245-253.

FERNANDES D. 2010. Interferência de plantas daninhas na produção e qualidade de frutos de melão nos sistemas de plantio direto e convencional. Mossoró: UFERSA, p.62 (Dissertação mestrado).

FREITAS FCL; FERREIRA LR; AGNES EL. 2005. Integração Agricultura/Pecuária. In: MARTINS CE; CÓSER AC; LEMOS AM; SOUZA AD; FRANCO PRV. (org). Aspectos técnicos, econômicos, sociais e ambientais da atividade leiteira. Juiz de Fora: editora. p. 111-126. v. 1.

INSTITUTO BRASILEIRO DE GEOGRAFIA E ESTATÍSTICA. Indicadores da produção agrícola. Banco de Dados 2009. Disponível em: http://www.sidra.ibge.gov.br/bda/tabela/ protabl.asp? $=1612 \& \mathrm{z}=\mathrm{t} \& \mathrm{o}=11 \& \mathrm{i}=\mathrm{P}$. Acesso em 14 de abril de 2011.

JUNIOR ASA; DIAS NS; FIGUEIREDO JUNIOR LGM; RIBEIRO VQ; SAMPAIO
DB. 2006. Produção e qualidade de frutos de melancia à aplicação de nitrogênio via fertirrigação. Revista Brasileira de Engenharia Agrícola e Ambiental 10: 836-841.

MACIEL CDG; POLETINE JP; VELINI ED; BELISÁRIO DRS; MARTINS FM; ALVES LS. 2008. Interferência de plantas daninhas no cultivo da melancia. Horticultura Brasileira 26: 1.07-111.

MEDEIROS RD; MOREIRA MAB; LUZ FJF; OLIVEIRA JÚNIOR JOL. 2000. Controle de plantas daninhas na cultura da melancia em Roraima. Horticultura Brasileira 18: 450-451.

SILVAAC; HIRATA EK; MONQUERO PA. 2009. Produção de palha e supressão de plantas daninhas por plantas de cobertura, no plantio direto do tomateiro. Pesquisa Agropecuária Brasileira 44: 22-28.

SILVA HIRATAAC; HIRATA EK; MONQUERO PA; GOLLA AR; NARITA N. 2009. Plantas de cobertura no controle de plantas daninhas na cultura do tomate em plantio direto. Planta Daninha 27: 465-472.

SMEDA RJ; WELLER S. 1996. Potential of rye (Secale cereale) for weed management in transplant tomatoes (Lycopersicon esculentum). Weed Science 44: 596-602.

SOARES IAA; FREITAS FCL; NEGREIROS MZ; FREIRE GM; AROUCHA EMM; GRANGEIRO LC; LOPES WAR; DOMBROSKI JLD. 2010. Interferência das plantas daninhas sobre a produtividade e qualidade de cenoura. Planta Daninha 28: 247-254.

TEÓFILO TMS; FREITAS FCL; MEDEIROS JF; SILVADF; GRANGEIRO LC; TOMAZ HVQ. 2012. Eficiência no uso da água e interferência de plantas daninhas no meloeiro cultivado nos sistemas de plantio direto e convencional. Planta Daninha 30: 547-556.

TOMAZ HVQ. 2008. Manejo de plantas daninhas crescimento e produtividade do meloeiro em sistemas de plantio direto e convencional. Mossoró: UFERSA. 67p. (Dissertação mestrado). 